\title{
Análise espacial das exportações brasileiras de açúcar com destaque ao nordeste no período de 2014 a 2017
}

\author{
Spatial analysis of brazilian sugar exports highlighting northeast in the period \\ from 2014 to 2017 \\ Adeilson Elias de Souza ${ }^{1}$ (D), Paulo Ricardo Feistel ${ }^{1}$ (D), Daniel Arruda Coronel ${ }^{1}$ (1) \\ ${ }^{1}$ Universidade Federal de Santa Maria (UFSM), Santa Maria, RS, Brasil. E-mails: adeilsonelias@outlook.com; \\ prfeistel@gmail.com; daniel.coronel@uol.com.br
}

Como citar: Souza, A. E., Feistel, P. R., \& Coronel, D. A. (2021). Análise espacial das exportações brasileiras de açúcar com destaque ao nordeste no período de 2014 a 2017. Revista de Economia e Sociologia Rural, 59(2), e220080.

https://doi.org/10.1590/1806-9479.2021.220080

Resumo: O objetivo do presente trabalho é analisar espacialmente as exportações de açúcar dos estados brasileiros, além de identificar os níveis de especialização e competitividade desse setor para essas áreas. Neste sentido, foi elaborada uma análise exploratória dos dados espaciais (AEDE), por meio do I de Moran global e local, e foram calculados os índices de quociente locacional, market share, participação relativa das exportações e participação do comércio de açúcar nos estados. Os resultados mostram que as exportações de açúcar dos estados brasileiros estão correlacionadas espacialmente. Nesse sentido, destaca-se a relação entre os estados do Paraná, São Paulo e Mato Grosso do Sul. Os índices relativos ao comércio internacional indicam níveis de especialização e competitividade concentradas em torno de um número reduzido de estados.

Palavras-chave: distribuição espacial, exportações de açúcar, Brasil.

Abstract: The objective of the present work is to analyze spatially the sugar exports of the Brazilian states, as well as to identify the levels of specialization and competitiveness of this sector in these areas. In this sense, it was elaborated an exploratory analysis of the spatial data (AEDE) through the global and local Moran I, and the calculation performance of the location quotient indexes, Market Share, relative participation of exports and participation of the sugar trade in the states. The results show that the sugar exports of the Brazilian states are spatially correlated, therefore, the relationship between the states of Paraná, São Paulo and Mato Grosso do Sul stands out. In addition, the relative indexes to international trade indicate levels of specialization and competitiveness concentrated around a reduced number of states.

Keywords: spatial distribution, sugar exports, Brazil.

\section{INTRODUÇÃO}

Os padrões de comércio entre os países no mundo estabelecem-se de acordo com a eficiência com que cada país produz determinados bens na economia. Assim, países abundantes em capital possuem vantagem comparativa em produzir bens industrializados e países com grandes extensões de terra apresentam vantagem comparativa em produzir bens agrícolas.

Atualmente, destaca-se a importância que os países vêm dando à produção de bens agrícolas, sobretudo pela necessidade de suprir a demanda alimentícia da população e pela relevância que as commodities possuem em relação ao setor industrial. Uma das principais commodities brasileiras comercializadas no mundo é o açúcar e, de acordo com dados do Ministério da Indústria, Comércio Exterior e Serviços (Brasil, 2019a), em 2018, o Brasil exportou 21,305 mil toneladas de açúcar e obteve a maior exportação dessa commodity do 
mundo, sendo seus principais países importadores, respectivamente, Argélia, Índia, Bangladesh, Emirados Árabes Unidos, Arábia Saudita e Nigéria.

De acordo com dados do MDIC (Brasil, 2019a), no Brasil, as exportações de açúcar são concentradas na região Sudeste, que exportou mais de $70 \%$ do total nacional; na região Sul, com uma média superior a $10 \%$ entre os quatro anos analisados; nas regiões Centro-Oeste e Nordeste, com respectivas médias de 7,81\% e 6,95\% entre o período de 2014 a 2017 . No âmbito do Nordeste, os principais estados produtores são Alagoas, com uma média de $71,71 \%$ de todas as exportações de açúcar da região Nordeste durante o período de 2014 a 2017, seguido de Pernambuco, com média de 25,42\%, e Paraíba, Sergipe e Rio Grande do Norte, com respectivas médias de 1,8\%, 0,69\% e 0,38\% das exportações nordestinas de açúcar.

Neste contexto, a problemática da pesquisa consiste em verificar uma possível correlação existente entre a quantidade das exportações de açúcar dos estados com a de seus vizinhos. Assim, surge o seguinte questionamento: as exportações de açúcar dos estados brasileiros estão correlacionadas espacialmente?

O presente texto tem como objetivo analisar quais estados brasileiros mais exportaram açúcar no período de 2014 a 2017; observar a correlação espacial entre os principais estados brasileiros exportadores de açúcar; identificar a especialização e competitividade do setor exportador de açúcar desses estados analisados.

A relevância da pesquisa está atrelada ao interesse em enriquecer evidências empíricas a respeito das exportações de açúcar nos estados brasileiros, principalmente nos estados nordestinos, pois como a região Nordeste possui baixa qualificação da mão de obra, a cultura agrícola nessa área possui grande importância para a geração de renda.

Neste trabalho, deseja-se verificar padrões de distribuição das exportações de umas das principais commodities nordestinas e também brasileiras - o açúcar -, realizando uma análise quantitativa dessas exportações nos estados brasileiros, e tentar identificar possíveis correlações entre as exportações de determinadas áreas com suas vizinhas. Para isso, é avaliado, por meio de uma análise espacial, através de uma metodologia de análise exploratória dos dados (Aede), o comportamento das exportações de açúcar nordestinas e brasileiras para o mundo, no período de 2014 a 2017.

O artigo está estruturado em quatro seções, além desta introdução. Na segunda seção, será apresentada uma análise das exportações de açúcar do Brasil e de como algumas políticas públicas influenciaram a produção do açúcar brasileiro. Na seção três, será apresentada a metodologia do modelo espacial do I de Moran e alguns indicadores de economia internacional. Na quarta seção, serão mostrados os resultados obtidos e suas respectivas análises. Por fim, na quinta seção, serão apresentadas as considerações finais do trabalho.

\section{EVOLUÇÃO DO COMÉRCIO DE AÇÚCAR NO BRASIL E NORDESTE}

O fim da forte presença do governo apoiando o processo de produção e exportação de açúcar na segunda metade da década de 1990 desencadeou mudanças nas relações de trabalho, afetou o sistema de controle e inovação agrícola e, consequentemente, sem as distorções nos custos e preços relativos causados pela postura desse agente governamental, o açúcar brasileiro se tornou mais competitivo no mercado externo.

De acordo com Vidal et al. (2006), a necessidade de tornar o setor sucroalcooleiro do Brasil mais eficiente ocasionou ganhos nos níveis de produtividade comparativamente a seus concorrentes, proporcionou redução dos custos de produção e a implantação de novas tecnologias na produção agrícola do açúcar.

De acordo com Bueno (2012), o fator logístico também é de enorme relevância na determinação do poder de competitividade do açúcar brasileiro, pois, além dos investimentos em infraestrutura e capital humano, os custos com transporte para exportação exercem um grande peso na determinação do preço do açúcar. Em relação ao processo inovativo e tecnológico do setor agrícola, pode-se observar a modernização nos manejos de irrigação das usinas e destilarias e o surgimento de plantas de cana-de-açúcar capazes de reduzir as pragas. 
Com o surgimento de maiores unidades de produção, a demanda por empregos se elevou e contribuiu para a elevação da renda nessas áreas produtoras.

Bueno (2012) destaca alguns pontos positivos e negativos encontrados pelos produtores de açúcar no âmbito da logística em direção às exportações. Do lado negativo, destacam-se as produções sazonais dessa cultura, que dificultam o planejamento das exportações; a dificuldade em concretizar estratégias produtivas a longo prazo; a infraestrutura de escoamento da produção precária devido aos baixos investimentos nessa área, além da insistência em utilizar rodovias em vez de linhas férreas, por exemplo. Em relação aos aspectos positivos, as características encontradas foram: a) a busca por novas tecnologias e modernizações nos processos produtivos; b) a profissionalização da mão de obra e, consequentemente, sua maior especialização; c) a busca por redução dos custos de logística internos à produção; d) a elevação nos investimentos em infraestrutura com o objetivo de melhorar a capacidade de armazenamento.

Além desses pontos destacados nos parágrafos anteriores, grande parte dos produtores de açúcar que não resolveram colocar o gerenciamento da produção nas mãos de profissionais qualificados e optaram pela gestão familiar atualmente possuem custos de produção mais elevados ou foram expulsos do mercado por não conseguirem concorrer com os demais produtores (Vidal et al., 2006).

Em relação ao comércio internacional do açúcar, de acordo com dados do Atlas da Complexidade Econômica (2016), o Brasil é o maior exportador mundial de açúcar, com valor das exportações correspondente a 10,8 bilhões de dólares, seguido da Tailândia, com \$2,39 bilhões e Austrália e Índia, com \$1,57 bilhões cada um. No contexto nacional, o açúcar foi a segunda commodity agrícola mais exportada do Brasil, representando 5,7\% do total das exportações nacionais, tendo sido superada apenas pela soja, que possui participação de 10,2\% das exportações totais do Brasil.

No Brasil, como se pode acompanhar na Tabela 1, as exportações de açúcar são bastante concentradas nas regiões do Centro-Oeste, Sudeste e Sul, com participações relativas nacionais do total exportado em 2014, respectivamente, de 7,2\%, 73,15\% e 11,09\%. Quanto às demais regiões, apenas o Nordeste apresentou um valor de exportações significativo: $8,56 \%$ do total exportado brasileiro.

Em relação a 2015 e 2016, as participações das regiões Nordeste e Sul em relação ao total exportado pioraram, tendo como referência 2014, e as do Centro-Oeste e Sudeste melhoraram ao fim desse período. Porém, o valor total exportado foi reduzido em 19,32\%, fato ocasionado também pela desvalorização do real em relação ao dólar, de 2014 até o início de 2016, e como a demanda por esse bem é inelástica, o preço mais baixo internacionalmente não impulsionou a demanda, diminuindo substancialmente o valor das exportações totais de açúcar nesse período. De acordo com dados do Banco Central do Brasil (2019) e do MDIC (Brasil, 2019a), a partir do segundo semestre de 2016, o real voltou a se valorizar em relação ao dólar e o valor das exportações de açúcar nacional aumentou em 37,23\% em relação a 2015.

Tabela 1. Valor das exportações de açúcar nas regiões do Brasil em porcentagem do total, durante o período de 2014 a 2017

\begin{tabular}{ccccc} 
Regiões & $\mathbf{2 0 1 4}$ & $\mathbf{2 0 1 5}$ & $\mathbf{2 0 1 6}$ & $\mathbf{2 0 1 7}$ \\
Norte & 0,00 & 0,00 & 0,0 & 0,10 \\
Nordeste & 8,56 & 8,77 & 5,0 & 5,47 \\
Centro-Oeste & 7,20 & 8,37 & 8,0 & 7,81 \\
Sudeste & 73,15 & 71,44 & 78,0 & 77,28 \\
Sul & 11,09 & 11,42 & 9,0 & 9,35 \\
\hline
\end{tabular}

Fonte: elaboração própria com base em dados da Secretaria de Comércio Exterior (Secex) (Brasil, 2019a).

Em 2017, o valor das exportações de açúcar do Brasil aumentou em 9,45\% em relação a 2016, por causa da melhora nos preços internacionais do açúcar e das poucas alterações da 
taxa de câmbio nacional. Em relação à participação das regiões brasileiras no total exportado, poucas mudanças foram observadas tendo como referência 2016.

Como o intuito do trabalho é analisar melhor as exportações de açúcar da região Nordeste, a Tabela 2 expõe as exportações dos estados nacionais situados nessa região, durante o período de 2014 a 2017, para mostrar como as exportações do açúcar nordestino estiveram concentradas espacialmente. Os estados de Bahia, Ceará e Piauí, que também compõem a região Nordeste, não constam na Tabela 2 porque não apresentaram exportações de açúcar durante o período correspondente.

Tabela 2. Valor das exportações de açúcar dos estados do Nordeste em porcentagem do total dessa região, durante o período de 2014 a 2017

\begin{tabular}{ccccc|} 
Nordeste & $\mathbf{2 0 1 4}$ & $\mathbf{2 0 1 5}$ & $\mathbf{2 0 1 6}$ & $\mathbf{2 0 1 7}$ \\
Alagoas & $\mathbf{7 3 , 1 4}$ & $\mathbf{7 0 , 7 0}$ & $\mathbf{7 1 , 4 9}$ & $\mathbf{7 1 , 5 1}$ \\
Pernambuco & 25,04 & 26,88 & 26,03 & 23,72 \\
Paraíba & 0,84 & 1,47 & 1,15 & 3,74 \\
Sergipe & 0,79 & 0,67 & 0,77 & 0,53 \\
Rio Grande do Norte & 0,18 & 0,28 & 0,57 & 0,49
\end{tabular}

Fonte: elaboração própria com base em dados da Secretaria de Comércio Exterior (Secex) (Brasil, 2019a).

Em relação à Tabela 2, pode-se observar a queda do valor da produção do açúcar nordestino durante o período analisado, reduzindo-se $22,65 \%$ o seu valor de 2014 para 2017, o que se deve à queda nas precipitações pluviométricas nessa região, conforme apontado pelo Instituto Nacional de Meteorologia (2019), o que dificultou a produção dessa commodity, e à diminuição do preço do açúcar no mercado internacional, de acordo com o Cepea/Esalq (Universidade de São Paulo, 2018), aliada à maior produção da Tailândia e da Índia. No que se refere aos estados nordestinos, conforme a Tabela 2, pode-se acompanhar a liderança que o estado de Alagoas possui em relação aos demais durante o período analisado, seguido dos estados de Pernambuco e da Paraíba. No entanto, o mais importante é ressaltar que o padrão de concentração das exportações de açúcar desses três estados, sobretudo o de Alagoas, se repete durante o período de 2014 a 2017.

A próxima seção traz uma revisão da literatura dos estudos mais recentes e relevantes que tratam sobre a produção sucroalcooleira no Brasil e no Nordeste, em específico, mostrando os principais resultados encontrados e apontando possíveis pontos que dificultam o progresso da produção do açúcar brasileiro.

\subsection{BREVE REVISÃO DA LITERATURA}

O comércio mundial de açúcar possui uma importante relevância no resultado da balança comercial brasileira e, consequentemente, na geração de renda de uma parte da população. Assim, alguns autores buscaram entender como se configura o setor açucareiro brasileiro de acordo com algumas variáveis de interesse, alcançando resultados referentes a diversas características do setor, como será mostrado a seguir.

As exportações do açúcar brasileiro são bastante influenciadas pelo fator logístico. Algumas características presentes desse fator nas exportações podem ser destacadas no trabalho de Bueno (2012), que teve o objetivo de identificar a opinião dos agentes que atuam nesse setor, por meio de um questionário, com a pretensão de analisar qualitativamente a cadeia logística das exportações de açúcar no Brasil. Os resultados indicaram que a logística apresentada é deficitária e a gestão administrativa é a principal responsável por eventuais sucessos nas operações logísticas brasileiras.

Shikida (2014) procurou apontar as principais características da evolução da agroindústria canavieira brasileira por meio de uma análise descritiva histórica do período 1946/1947 a 2012/2013. Em relação aos resultados alcançados, conclui-se que o açúcar brasileiro sofreu forte interferência governamental e é carente de uma correta regulamentação institucional para atender aos principais interesses do setor. 
Outra análise foi realizada por Dias et al. (2006), que estudaram a competitividade do setor exportador de açúcar do Brasil no comércio internacional, por meio do indicador de market share, identificando uma forte concentração de 40,61\% do comércio de açúcar no mundo atrelada à figura do Brasil em 2005. Além disso, também se destacou que o açúcar brasileiro possui vantagem competitiva em relação ao mercado internacional, sendo também uma importante fonte de geração de divisas.

Ao seguir essa linha de estudo, Ferreira et al. (2009) analisaram os efeitos dos preços internacionais e da taxa de câmbio na receita das exportações de açúcar, no período de 1989 a 2007, por meio do modelo shift-share ou diferencial-estrutural, apontando que as variações das receitas geradas nas exportações de açúcar estão associadas às variações dos preços internacionais, enquanto o câmbio não exerceu tanta influência nas variações da receita gerada nas exportações dessa commodity.

Ao realizarem trabalhos com níveis de aplicação maior que os anteriormente citados, Costa et al. (2006) estimaram, em seu trabalho, o impacto das exportações de açúcar no nível de emprego e produção do Brasil, por meio de uma matriz de insumo-produto inter-regional referente à economia brasileira, segundo a qual concluíram que o impacto resultante de um choque na demanda sobre o emprego e produção situados nas regiões Norte e Nordeste é de maior magnitude de que nas regiões Centro-Oeste, Sudeste e Sul.

O trabalho de Alves \& Bacchi (2004) também possui um viés mais aplicado e buscou estimar, por meio de um modelo de autorregressão vetorial, a função de oferta das exportações de açúcar do Brasil, no período de 1995 a 2002. Os resultados obtidos nesse trabalho mostram que a desvalorização cambial e o aumento no preço das exportações exercem um impacto expressivo nas exportações brasileiras, enquanto o aumento do preço doméstico e o da renda nacional exercem efeitos negativos sobre o volume exportado, sendo a renda interna a variável que possui maior impacto nas variações das exportações.

Ao destacarem o setor sucroalcooleiro no Nordeste, Vidal et al. (2006) buscaram, por meio da análise da cadeia produtiva, detalhar o setor sucroalcooleiro brasileiro e do Nordeste de forma mais específica, por meio de entrevistas, observações nas visitas e pesquisas bibliográficas. Os resultados alcançados mostram que o setor sucroalcooleiro do Nordeste apresenta custos somente maiores que os da região Centro-Sul do Brasil. Sendo assim, esse setor se mostra competitivo no mercado externo. Além disso, para que ocorra uma ampliação da produção de açúcar no Nordeste, esta deve focalizar os estados do Piauí e do Maranhão.

\section{METODOLOGIA}

Esta seção está dividida em duas partes: a primeira traz a metodologia dos índices calculados a respeito do comércio internacional e a segunda relata a metodologia da análise exploratória dos dados (AEDE) utilizada para obter o índice de Moran global e o local. Os dados utilizados neste trabalho foram todos coletados no Ministério da Indústria, Comércio Exterior e Serviços (MDIC), com exceção dos dados sobre emprego no setor açucareiro, extraídos da Relação Anual de Serviços Sociais (RAIS).

\subsection{METOdOLOGIA DOS ÍNDICES REFERENTES AO COMÉRCIO INTERNACIONAL}

De acordo com o trabalho de Dias et al. (2006), pode-se efetuar o cálculo de alguns índices referentes ao comércio internacional de açúcar, realizando algumas alterações nesses determinados índices para a melhor adequação ao trabalho. Nesta seção, também é calculado o quociente locacional, como é definido por Monasterio (2011).

Os índices referentes ao comércio internacional mostrados nesta seção possuem o objetivo de verificar os níveis de especialização, de concentração e de competitividade das exportações brasileiras de açúcar, durante o período de 2014 a 2017, por meio dos cálculos referentes aos estados brasileiros em âmbito nacional. São eles: o quociente locacional, o indicador de market share ou parcela do mercado, o de participação relativa do açúcar nas exportações totais e o do comércio de açúcar em relação ao comércio total dos produtos agrícolas. 


\subsubsection{Quociente locacional}

Dentre os índices apresentados e calculados neste trabalho, o coeficiente de concentração mede a participação das exportações de açúcar no total exportado na área $i$, dividido pela participação do açúcar nas exportações totais da região $j$. Esse índice pode ser apresentado formalmente segundo Monasterio (2011) como:

$Q_{L K i}=\frac{\frac{V_{k i}}{V_{i}}}{\frac{V_{k j}}{V j}}$

Em que $V_{k i}$ refere-se ao valor das exportações de açúcar nos estados brasileiros; $V_{i}$ é o valor das exportações totais desses mesmos estados; $V_{k j}$ é o valor das exportações nacionais de açúcar; $V_{j}$, o valor das exportações totais em todo o país.

Em relação ao resultado desse indicador, caso apresente um valor maior que uma unidade, isso indica que o estado em questão é especializado na produção de açúcar. Para valores resultantes menores que uma unidade, isto implica que a participação na produção de açúcar no estado $i$ é menor que na região j (Monasterio, 2011).

\subsubsection{Market share}

Um importante indicador capaz de identificar a posição do comércio do produto de um determinado bem, em relação ao mundo, é o market share ou posição no mercado. Esse índice relaciona as exportações estaduais de açúcar divididas pelas exportações nacionais do mesmo produto, sendo essa razão denominada de participação percentual das exportações de açúcar do Brasil no comércio internacional do açúcar, definido por Dias et al. (2006) como:

$S_{k i}=\frac{X_{k i}}{X_{k B}} \cdot 100$

Em que $x$ se refere ao valor das exportações; $k$ é o açúcar; $i$ são os estados; $B$, o Brasil.

O resultado desse indicador varia entre zero e cem, pois está expresso em termos de porcentagem. Assim, a interpretação desse cálculo aponta que, quanto maior for o valor obtido, maior será a participação das exportações de açúcar do determinado estado no comércio internacional.

\subsubsection{Participação relativa do açúcar nas exportações totais}

Um indicador similar ao de market share, conforme foi apresentado anteriormente, é o da participação das exportações de açúcar sobre o total exportado, com a diferença de que enquanto aquele relaciona as exportações de açúcar nos estados em relação às exportações nacionais desse produto, este se refere às exportações totais de cada estado. Assim, esse índice apresenta a concentração das exportações de açúcar em torno das exportações totais estaduais e pode ser obtido de maneira formal por Dias et al. (2006) da seguinte forma:

$X_{R i}=\frac{X_{k i}}{X_{i}} \cdot 100$

Onde $X_{k i}$ representa as exportações de açúcar dos estados e $X_{i}$ refere-se às exportações totais estaduais. Em relação à análise desse indicador, também é apresentado na forma de porcentagem. Dessa forma, quanto maior for o valor obtido, maior será a parcela das exportações de açúcar em relação ao total exportado em cada estado. 


\subsubsection{Comércio de açúcar em relação ao comércio total dos produtos}

Um indicador mais geral que os mostrados anteriormente é o do comércio de açúcar em relação ao comércio total dos produtos, em que se apresenta a participação da soma entre exportações e importações de açúcar dos estados em relação ao somatório das exportações e importações de açúcar no Brasil. É formalmente definido por Dias et al. (2006) como:

$q_{k i}=\frac{X_{k i}+M_{k i}}{X_{i}+M_{i}} \cdot 100$

Em que $X_{k i}$ representa as exportações de açúcar dos estados brasileiros, $M_{k i}$ são as importações de açúcar dos estados, $x_{i}$ refere-se às exportações totais dessas unidades federativas e $M_{i}$, às suas importações totais. Em relação ao resultado desse índice, também é expresso em termos de porcentagem e, a partir de sua análise, pode-se concluir que quanto maior for $0 q_{k i}$, que é a razão do comércio de açúcar no Brasil em relação ao comércio mundial do mesmo bem, maior será a participação do intercâmbio de comércio de açúcar dos estados brasileiros em relação ao do comércio internacional do Brasil.

\subsection{ANÁLISE EXPLORATÓRIA DE DADOS ESPACIAIS (AEDE)}

Neste trabalho, é elaborada uma análise exploratória dos dados espaciais (Aede) para verificar como se comporta a distribuição espacial das exportações de açúcar dos estados brasileiros no período de 2014 a 2017, comparando-os e tentando identificar possíveis alterações nos padrões de distribuição das exportações brasileiras de açúcar.

Segundo Almeida (2012), a Aede conta com uma série de técnicas capazes de identificar padrões de associação espacial por meio do índice de Moran local, que trazem algumas funções, como análise de clusters espaciais, verificação de distribuições de concentração de determinada variável espacialmente e busca das observações incomuns, chamadas de outliers espaciais pela literatura.

No presente trabalho, é tratado por meio da Aede o índice de Moran (I de Moran) global univariado e o bivariado, buscando-se identificar tanto a autocorrelação espacial global das exportações de açúcar por meio dos estados brasileiros como a correlação espacial entre as variáveis exportações de açúcar e produto interno bruto dos estados. Além deste citado, também é utilizado o I de Moran local univariado e o bivariado, chamados de Local Indicator of Spatial Association (LISA), que captam a formação de clusters espaciais entre uma determinada área e suas regiões vizinhas, formando um conglomerado. A análise univariada e a bivariada local também seguem a mesma lógica da global explicada neste parágrafo.

\subsubsection{Autocorrelação espacial global univariada}

Em um estudo de análise exploratória dos dados espaciais, é de crucial importância verificar se os dados são distribuídos aleatoriamente, ou seja, se os valores de uma determinada variável em uma área não são afetados pelos valores dessa mesma variável em suas áreas vizinhas. Para obter uma medida de autocorrelação espacial, é preciso ter uma medida de variância dos dados, uma medida de autocovariância e, por fim, a matriz de ponderação espacial também denominada de matriz W (Almeida, 2012).

Moran (1948) elaborou, com base em uma medida de autocovariância seguindo a forma de um produto cruzado, o primeiro coeficiente de autocorrelação espacial, chamado de I de Moran, que pode ser obtido formalmente pela Equação 5.

$I=\frac{\sum_{i=1}^{n} \sum_{j=1}^{n} w_{i j} y_{i} y_{j}}{\sum_{i=1}^{n} y_{i}^{2}}$

Em que n é o número de observações, $w_{i j}$ são os elementos da matriz de pesos espaciais e $y_{i}$ e $y_{j}$ correspondem aos valores da variável em análise. Neste caso, as exportações de 
açúcar nas unidades federativas brasileiras foram calculadas por meio dos desvios em relação à média.

Em relação à hipótese a ser testada, a hipótese nula indica aleatoriedade dos dados espaciais. Assim, não se pode trabalhar com ferramentas de análise espacial. A hipótese alternativa é que os dados são autocorrelacionados espacialmente, o que viabilizaria os estudos espaciais nessa área. Os valores encontrados situados abaixo do valor esperado [1/(n-1)] sinalizam correlação espacial negativa e, de forma análoga, os situados acima desse valor apresentam correlação espacial positiva. Em suma, as informações disponibilizadas pelo I de Moran são a significância estatística sobre a aleatoriedade espacial dos dados; o sinal negativo indica que os dados estão dispersos e o sinal positivo, caso seja significativo, indica concentração dos dados espacialmente em torno das áreas selecionadas (Almeida, 2012).

\subsubsection{Autocorrelação espacial global bivariada}

De acordo com Almeida (2012), a ideia da autocorrelação global bivariada é identificar se existe uma associação espacial entre os valores de uma variável com os de outra, analisando a distribuição dessas variáveis em determinadas áreas com suas regiões vizinhas em âmbito global e verificando um possível padrão espacial entre essas duas variáveis distintas. A verificação da existência de autocorrelação espacial global entre essas variáveis será usada para viabilizar ou não o uso de modelos econométricos espaciais.

Formalmente, o índice de autocorrelação global bivariada pode ser obtido da seguinte forma:

$I^{z_{1} z_{2}}=\frac{z_{1} W z_{2}}{z_{1} z_{2}}$

Em que $z_{1}$ e $z_{2}$ são variáveis distintas padronizadas e $\mathrm{W}$, a matriz de pesos espaciais. $\mathrm{O}$ termo no numerador da identidade anterior corresponde a um cálculo da covariância do tipo produto cruzado e a expressão situada no denominador refere-se a uma medida de reescalonamento, utilizando, para isso, a variância dos dados que se pretende analisar (Almeida, 2012).

\subsubsection{Autocorrelação espacial local univariada}

Com o intuito de verificar a relação espacial local por meio do $I_{i}$ de Moran local, deve-se calcular o indicador de autocorrelação espacial local (LISA) para cada região da amostra em quatro tipos de classes relevantes (AA, BB, $A B$ e BA). Esses grupos indicam, respectivamente, as relações do tipo alto-alto, em que valores altos de uma variável em uma área são seguidos de valores também altos em suas áreas vizinhas; baixo-baixo, que, de forma análoga, indica que valores baixos em uma determinada região são acompanhados de valores também baixos em suas vizinhas; alto-baixo, valores altos acompanhados de vizinhos com valores baixos; baixo-alto, valores baixos em determinada área agrupados com valores altos em suas regiões vizinhas, classificando, dessa forma, todas as áreas de modo individual. Por meio da Equação 7, pode-se obter formalmente esse indicador por meio de uma variável padronizada y localizada na região i (Almeida, 2012):

$I_{i}=z_{i} \sum_{j=1}^{j} w_{i j} z_{j}$

Em que $z_{i}$ se refere ao valor das exportações de açúcar do estado i padronizada, W corresponde à matriz de pesos espaciais e $z_{j}$, à variável padronizada do valor das exportações de açúcar no estado j.

Em relação aos resultados calculados do $I_{i}$ de Moran local, este busca examinar a associação espacial linear obtida para cada área delimitada espacialmente. Para cada área do 
espaço demarcado, é obtido um $I_{i}$. Dessa forma, torna-se possível obter um número $\mathrm{n}$ de aquisições da estatística calculada $I_{i}$ e os seus correspondentes níveis de significância. Porém, como se torna inviável ou mais trabalhoso observar os valores isoladamente, uma maneira de tornar mais prática e interativa a análise é mapear os valores obtidos de acordo com a localização espacial das observações (Almeida, 2012).

\subsubsection{Autocorrelação espacial local bivariada}

De acordo com Almeida (2012), da mesma forma que se obtém um coeficiente de autocorrelação espacial global para uma análise bivariada, pode-se também realizar uma análise local bivariada. Supondo que existam duas variáveis que se pretende analisar, denominadas de $y_{i}$ e $x_{i}$, e, depois de padronizá-las, estas passam a ser chamadas de $z_{l i}$ e $z_{2 i}$, introduzindo essas informações no I de Moran local, pode-se obter formalmente a seguinte identidade.

$I_{i}^{z_{1} z_{2}}=z_{1 i} W z_{2 i}$

Em que $\mathrm{W}_{z_{2 i}}$ corresponde à defasagem espacial na qual se encontra a variável padronizada $z_{2 i}$. Segundo Anselin (2003), esse indicador serve para dar uma ideia de como se comporta a associação espacial linear, que pode ser positiva ou negativa a respeito de uma variável em uma dada região, e a média da outra variável nas intermediações das áreas vizinhas.

\section{ANÁLISE DOS RESULTADOS}

De acordo com o MDIC (Brasil, 2019a), o Brasil, entre 2014 e 2016, apresentou queda no valor das exportações de açúcar, reduzindo seu valor de \$11.374.586.847,00, em 2014, para \$ 7.569.995.882,00, em 2016, tendo voltando a aumentar para \$ 9.388.352.958,00, em 2017. As variações no valor das exportações brasileiras de açúcar foram acompanhadas por reduções na quantidade de pessoas empregadas nesse setor, que declina de 449.554, em 2014, para 410.250, em 2016, segundo dados da RAIS (Brasil, 2019b).

A relação entre valor das exportações e número de empregados faz sentido na prática, conforme foi colocado por Costa et al. (2006), os quais estimaram, em seu trabalho, o impacto das exportações de açúcar no nível de emprego nacional, por meio de uma matriz de insumoproduto inter-regional referente à economia brasileira.

Na Figura 1, pode-se observar, no eixo da esquerda, os valores referentes ao valor das exportações de açúcar do Brasil, expressos em dólares, e, no eixo direito, é situado o número de empregados no setor açucareiro nacional, no período de 2014 a 2017.

A queda do número de empregados no setor sucroalcooleiro pode ainda ser maior caso se considere que este ainda é um setor que possui muitos empregos informais, os quais não foi possível identificar nas estatísticas expostas neste trabalho. Em 2017, os empregos no setor de açúcar continuaram a cair, chegando a 404.057 empregados, ainda que os valores das exportações de açúcar tenham aumentado. No entanto, a queda do número de empregados, que foi de 3,18\% de 2015 a 2016, reduziu-se a uma queda de 1,53\% na passagem de 2016 a 2017.

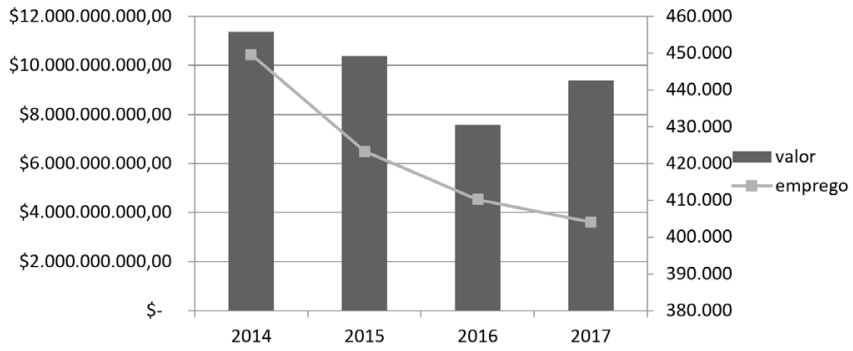

Figura 1. Valor das exportações brasileiras de açúcar (eixo esquerdo) e número de empregos no setor sucroalcooleiro nacional no período de 2014 a 2017. Fonte: elaborada pelo autor com base em dados do MDIC e da RAIS (Brasil, 2019a, 2019b). 
Com o intuito de verificar a distribuição espacial das exportações de açúcar nacionais distribuídas pelas unidades federativas brasileiras, elaboraram-se, na Figura 2, dividida entre partes "A" e "B", os mapas de concentração dos valores das exportações brasileiras de açúcar em 2014 e 2017.

(A) valor das exportações de açúcar 2014

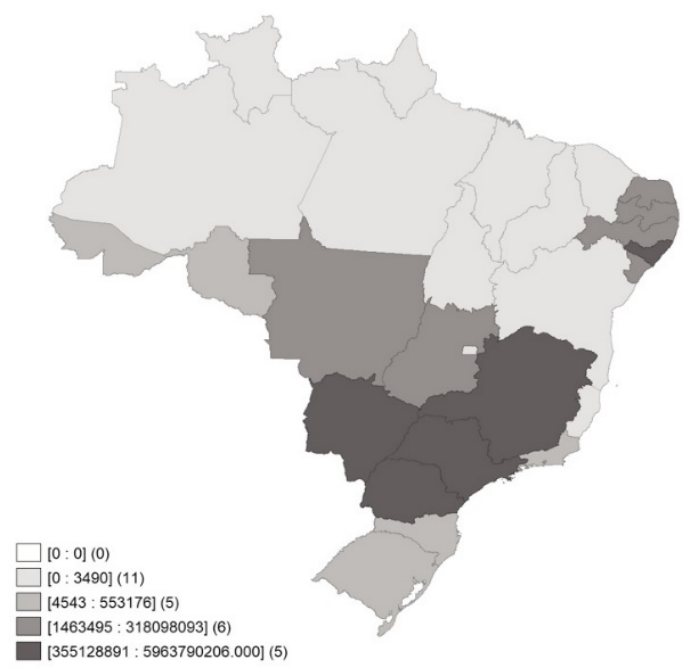

(B) valor das exportações de açúcar 2017

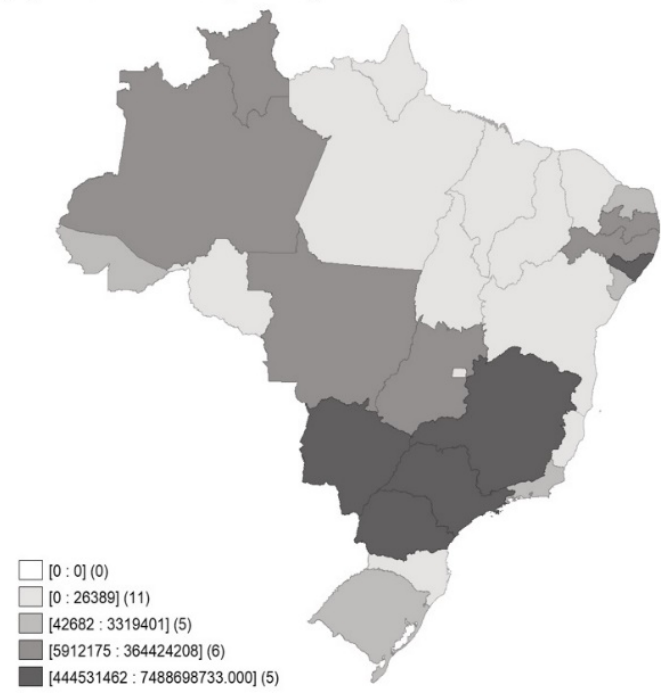

Figura 2. Distribuição espacial do valor das exportações brasileiras de açúcar por unidades federativas em 2014 e 2017. Fonte: elaboração própria com base nos dados do MDIC (Brasil, 2019a).

De acordo com os mapas (A) e (B), referentes a 2014 e 2017, pode-se observar a distribuição do valor das exportações brasileiras de açúcar, por meio das classificações de acordo com as classes de cores, as quais vão da cor mais clara (menores valores) às mais escuras (maiores valores). No mapa (A), referente a 2014, pode-se observar que a classe mais escura, correspondente aos estados com maiores valores das exportações de açúcar, está concentrada nos estados do Paraná, de Mato Grosso do Sul, de São Paulo, de Minas Gerais e de Alagoas, em um intervalo de valores que vai de \$355.128.891 a \$5.963.790.206. Na segunda classe com os maiores valores, em um intervalo de \$1.463.495 a \$318.098.093, encontram-se os estados de Goiás, Mato Grosso, Rio Grande do Norte, Paraíba, Pernambuco e Sergipe.

No mapa (B), referente a 2017, toma-se como exemplo a análise do mapa (A), dividindo-se os valores observados das exportações brasileiras de açúcar em classes de acordo com as cores correspondentes. No intervalo com os maiores valores, que são distribuídos entre \$444.531.462 e \$ 7.488.698.733, continuam os mesmos estados que pertenciam a esse grupo em 2014: Alagoas, Minas Gerais, São Paulo, Paraná e Mato Grosso do Sul. No segundo grupo com maiores valores das exportações de açúcar, houve algumas alterações em relação a 2014, como a saída de Rio Grande do Norte e Sergipe e a entrada de Amazonas e Roraima, que sequer apresentaram dados de exportação de açúcar em 2014, mas que, no decorrer dos anos, aumentaram significantemente as exportações. Aliado a isso, no cenário atual, as exportações de açúcar da região Norte vêm mostrando uma pequena elevação, enquanto, no Nordeste, alguns estados aumentam as exportações de açúcar e outros diminuem.

A respeito da avaliação dos dois mapas pertencentes à Figura 2, destaca-se a enorme disparidade do valor das exportações de açúcar em São Paulo em relação aos demais estados, tendo sido, isoladamente, em 2014, representante de 63,5\% de todas as exportações brasileiras de açúcar e, em 2017, chegado a 65,8\% do total nacional.

Este trabalho, além de analisar como se comportam as exportações de açúcar durante o período de análise do estudo em relação ao Brasil, também tem o interesse em enfatizar a distribuição espacial dos estados com maiores valores das exportações na região Nordeste. Para isso, mostram-se, na Figura 3A, exportações em 2014, e na parte (B) referente a 2017, a 
distribuição espacial das exportações de açúcar separadamente em relação aos estados da referida região.

(A) valor das exportações de açúcar 2014
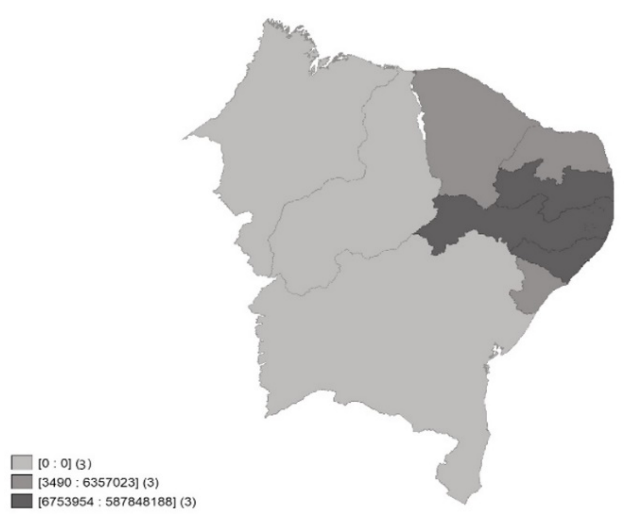

(B) valor das exportações de açúcar 2017

Figura 3. Distribuição espacial do valor das exportações brasileiras de açúcar no Nordeste em 2014 e 2017. Fonte: elaboração própria com base em dados do MDIC (Brasil, 2019a).

Na Figura 3, são divididos os estados com maiores valores das exportações de açúcar, agrupados em três classes de acordo com os valores observados. Os três estados que apresentaram maiores níveis de exportação são Paraíba, Pernambuco e Alagoas, representando, respectivamente, $0,84 \%, 25,04 \%$ e $73,14 \%$ das exportações totais nordestinas, e, se somar as participações das exportações de açúcar desses três estados, isto totaliza 99,01\% do total exportado na região Nordeste.

Em relação a 2017, os três estados nordestinos com maiores valores das exportações de açúcar continuam sendo os mesmos observados em 2014, conforme demonstrado em parágrafo anterior, e, nesse ano, a participação das exportações dos estados de Pernambuco e Alagoas no total da região Nordeste diminuiu, enquanto a da Paraíba aumentou de 0,84\% a $3,74 \%$. Duas mudanças que podem ser vistas na comparação entre os mapas de 2014 e 2017 é a saída do Ceará do segundo grupo com maiores valores e a inclusão do estado do Maranhão.

Além da contextualização dos valores das exportações de açúcar do Brasil e, posteriormente, enfatizando a dos estados da região Nordeste, esta seção é dividida em duas partes principais: a primeira se refere aos cálculos dos índices referentes ao comércio internacional de açúcar dos estados brasileiros e a segunda está relacionada à análise exploratória dos dados espaciais (AEDE), na qual se utilizou o I de Moran global e local para identificar os padrões de associação espacial do valor das exportações de açúcar presentes no Brasil.

\section{1 ÍNDICES REFERENTES AO COMÉRCIO INTERNACIONAL}

Para verificar os níveis de especialização e inserção dos estados brasileiros no comércio internacional, foram calculados os devidos índices retratados na metodologia deste trabalho, que podem ser visualizados ao longo desta seção.

O primeiro índice a ser tratado é o quociente locacional, que é composto da razão entre a participação das exportações de açúcar em relação às exportações totais de cada estado e a participação das exportações de açúcar do Brasil em relação ao total exportado nacionalmente. Esse índice verifica se cada estado é mais especializado na produção de açúcar que o Brasil. Os valores obtidos podem ser visualizados na Tabela 3.

$\mathrm{Na}$ Tabela 3, podem-se observar os valores calculados do quociente locacional para 15 dos 27 estados brasileiros, com a justificativa de que os demais não apresentaram valores diferentes de zero para todos os anos analisados de 2014 a 2017. Em relação aos resultados obtidos, destaca-se a elevada especialização das exportações de açúcar em relação ao total 
exportado por Alagoas para todos os anos, sendo, de forma disparada, o estado com maior especialização nas exportações de açúcar no Brasil.

Tabela 3. Valor das exportações de açúcar: quociente locacional por unidades federativas no período de 2014 a 2017

\begin{tabular}{ccccc} 
Estados & $\mathbf{2 0 1 4}$ & $\mathbf{2 0 1 5}$ & $\mathbf{2 0 1 6}$ & $\mathbf{2 0 1 7}$ \\
Acre & $\mathbf{0 , 2 5 6 2}$ & $\mathbf{0 , 0 3 7 7}$ & 0,0526 & 0,0454 \\
Alagoas & 18,4200 & 12,7724 & 21,0181 & 15,3874 \\
Amazonas & 0,0000 & 0,0000 & 0,1004 & 0,2022 \\
Goiás & 0,8992 & 0,8732 & 1,5624 & 1,2153 \\
Mato Grosso & 0,0039 & 0,0096 & 0,0277 & 0,0369 \\
Mato Grosso do Sul & 1,3426 & 1,3408 & 2,6696 & 2,4186 \\
Minas Gerais & 0,6081 & 0,6638 & 1,2654 & 1,1777 \\
Paraíba & 0,7435 & 1,2641 & 1,1690 & 3,8030 \\
Paraná & 1,2574 & 1,0577 & 1,5373 & 1,3502 \\
Pernambuco & 4,2163 & 3,1196 & 2,2729 & 1,7306 \\
Rio Grande do Norte & 0,1150 & 0,1068 & 0,2462 & 0,2320 \\
Rio Grande do Sul & 0,0006 & 0,0034 & 0,0088 & 0,0024 \\
Roraima & 0,0000 & 0,0017 & 0,3951 & 3,9154 \\
São Paulo & 2,2979 & 1,8523 & 3,6300 & 3,4037 \\
Sergipe & 1,6107 & 0,8545 & 0,8373 & 0,8407 \\
\hline
\end{tabular}

Fonte: elaboração própria com base em dados da Secretaria de Comércio Exterior (SECEX) (Brasil, 2019a).

Retomando a descrição do índice, os estados que apresentarem valores maiores que a unidade são mais especializados nas exportações de açúcar que o Brasil de forma geral. Então, com base nos valores resultantes, pode-se concluir que, em 2014, os estados especializados foram Alagoas, Mato Grosso do Sul, Paraná, Pernambuco, São Paulo e Sergipe. Em 2017, último ano analisado, os estados foram Alagoas, Goiás, Mato Grosso do Sul, Minas Gerais, Paraíba, Paraná, Pernambuco, Roraima e São Paulo. No entanto, somente os estados de Alagoas, Mato Grosso do Sul, Paraná, Pernambuco e São Paulo apresentaram valores correspondentes à devida especialização em todos os anos analisados na Tabela 3.

Outro importante índice, referente ao comércio internacional, é o market share, bastante usado nos trabalhos na área de economia internacional, como no trabalho de Dias et al. (2006). Portanto, foram obtidos valores para esse índice em relação aos estados brasileiros, excluindo aqueles que apresentaram resultados muito próximos a zero, para facilitar a análise da Tabela 4 referente ao índice de market share.

Em relação aos resultados obtidos na Tabela 4, pode-se concluir que o estado de São Paulo é detentor de mais de $60 \%$ das exportações totais de açúcar do Brasil em todos os anos analisados, indicando, assim, um elevado nível de dependência do setor açucareiro brasileiro em torno desse estado. Depois de São Paulo, aparecem Minas Gerais e Paraná, com participações oscilando em torno de $10 \%$ no período analisado. Um importante ponto negativo que pode ser visualizado nessa tabela é a forte queda da participação das exportações de açúcar de Alagoas e, consequentemente, da região Nordeste, pois mais de $70 \%$ das exportações de açúcar de toda essa região pertencem a esse estado.

Com o interesse em verificar a participação das exportações de açúcar em relação ao total exportado de cada estado, foram calculados o índice de participação relativa para cada estado brasileiro, excluindo-se os que apresentaram participações muito próximas a zero. Assim, na Tabela 5, podem-se observar as participações de cada unidade federativa analisada. 
Tabela 4. Valor das exportações de açúcar: market share por unidades federativas no período de 2014 a 2017

\begin{tabular}{|c|c|c|c|c|}
\hline Estados & 2014 & 2015 & 2016 & 2017 \\
\hline Alagoas & $6,2147 \%$ & $6,1398 \%$ & $3,4970 \%$ & $3,8953 \%$ \\
\hline Amazonas & $0,0000 \%$ & $0,0000 \%$ & $0,0228 \%$ & $0,0518 \%$ \\
\hline Goiás & $3,3629 \%$ & $3,6648 \%$ & $3,6622 \%$ & $3,1934 \%$ \\
\hline Mato Grosso & $0,0312 \%$ & $0,0894 \%$ & $0,1376 \%$ & $0,2071 \%$ \\
\hline Mato Grosso do Sul & $3,7544 \%$ & $4,5367 \%$ & $4,2966 \%$ & $4,4055 \%$ \\
\hline Minas Gerais & $9,5538 \%$ & $10,4350 \%$ & $10,9647 \%$ & $11,3628 \%$ \\
\hline Paraíba & $0,0714 \%$ & $0,1278 \%$ & $0,0561 \%$ & $0,2037 \%$ \\
\hline Paraná & $10,9973 \%$ & $11,2738 \%$ & $9,2196 \%$ & $9,2923 \%$ \\
\hline Pernambuco & $2,1279 \%$ & $2,3341 \%$ & $1,2731 \%$ & $1,2924 \%$ \\
\hline Rio Grande do Norte & $0,0155 \%$ & $0,0243 \%$ & $0,0277 \%$ & $0,0269 \%$ \\
\hline Rio Grande do Sul & $0,0058 \%$ & $0,0429 \%$ & $0,0574 \%$ & $0,0161 \%$ \\
\hline São Paulo & $63,0492 \%$ & $60,3234 \%$ & $66,2907 \%$ & $65,6217 \%$ \\
\hline Sergipe & $0,0672 \%$ & $0,0584 \%$ & $0,0375 \%$ & $0,0291 \%$ \\
\hline
\end{tabular}

Fonte: elaboração própria com base nos dados da Secretaria de Comércio Exterior (SECEX) (Brasil, 2019a).

Tabela 5. Valor das exportações de açúcar: participação relativa do açúcar nas exportações totais por unidades federativas no período de 2014 a 2017

\begin{tabular}{ccccc} 
Estados & $\mathbf{2 0 1 4}$ & $\mathbf{2 0 1 5}$ & $\mathbf{2 0 1 6}$ & $\mathbf{2 0 1 7}$ \\
Acre & $\mathbf{1 , 2 9 9 4} \%$ & $\mathbf{0 , 2 0 6 1 \%}$ & $\mathbf{0 , 2 1 6 9 \%}$ & $0,1971 \%$ \\
Alagoas & $\mathbf{9 3 , 4 3 6 1 \%}$ & $\mathbf{6 9 , 7 8 9 7 \%}$ & $\mathbf{8 6 , 7 0 5 1 \%}$ & $\mathbf{6 6 , 8 4 5 3 \%}$ \\
Amazonas & $\mathbf{0 , 0 0 0 0 \%}$ & $0,0000 \%$ & $0,4143 \%$ & $0,8785 \%$ \\
Goiás & $\mathbf{4 , 5 6 1 4} \%$ & $4,7712 \%$ & $6,4452 \%$ & $5,2793 \%$ \\
Mato Grosso & $0,0200 \%$ & $0,0523 \%$ & $0,1141 \%$ & $0,1605 \%$ \\
Mato Grosso do Sul & $6,8103 \%$ & $7,3265 \%$ & $11,0129 \%$ & $10,5066 \%$ \\
Minas Gerais & $3,0845 \%$ & $3,6268 \%$ & $5,2202 \%$ & $5,1161 \%$ \\
Paraíba & $3,7715 \%$ & $6,9070 \%$ & $4,8224 \%$ & $16,5207 \%$ \\
Paraná & $6,3782 \%$ & $5,7794 \%$ & $6,3419 \%$ & $5,8656 \%$ \\
Pernambuco & $21,3872 \%$ & $17,0458 \%$ & $9,3762 \%$ & $7,5181 \%$ \\
Rio Grande do Norte & $0,5835 \%$ & $0,5836 \%$ & $1,0158 \%$ & $1,0079 \%$ \\
Rio Grande do Sul & $0,0030 \%$ & $0,0187 \%$ & $0,0361 \%$ & $0,0103 \%$ \\
São Paulo & $11,6562 \%$ & $10,1212 \%$ & $14,9746 \%$ & $14,7862 \%$ \\
Sergipe & $8,1704 \%$ & $4,6689 \%$ & $3,4541 \%$ & $3,6522 \%$ \\
\hline
\end{tabular}

Fonte: elaboração própria com base nos dados da Secretaria de Comércio Exterior (SECEX) (Brasil, 2019a).

Os resultados encontrados na Tabela 5 mostram que o estado de Alagoas é bastante dependente das exportações de açúcar, com valores acima de $60 \%$ em todos os anos analisados, porém destaca-se a queda dessa participação, que chegou a 93,43\%, em 2014, a $66,84 \%$, em 2017, impulsionada pela queda nas exportações de açúcar alagoana. Outro destaque importante na Tabela 5 é que, apesar da elevada magnitude das exportações de açúcar do estado de São Paulo, essa participação não se mostra tão grande como a de Alagoas, por conta do alto valor exportado daquele estado em outros produtos, o que não acontece com o estado nordestino.

Além dos índices citados ao longo desta seção, outro indicador utilizado é o do comércio de açúcar em relação ao comércio total de produtos. Assim, por meio da Tabela 6, podem-se visualizar os resultados obtidos desse indicador.

Esse índice é obtido por meio da razão entre a soma das exportações mais importações de açúcar e a soma entre exportações e importações totais. A diferença desse indicador para o da participação relativa é que este incorpora as importações no cálculo. Em relação aos 
resultados encontrados, é possível observar uma enorme concentração de açúcar no comércio internacional do estado de Alagoas, embora apresente importante queda nessa participação, que era de 49,27\%, em 2014, e passou a ser de 33,95\%, em 2017, resultante da diminuição nas exportações alagoanas durante esse período. Outra importante participação é a do estado de São Paulo, que apresenta uma pauta de exportação e importação bem densa e diversificada relativamente aos demais estados brasileiros, porém o comércio do açúcar nesse estado, em 2017, passou a representar 7,07\% do total do comércio internacional paulista.

Tabela 6. Valor das exportações de açúcar: comércio de açúcar em relação ao comércio total dos produtos por unidades federativas no período de 2014 a 2017

$\begin{array}{ccccc}\text { Estados } & \mathbf{2 0 1 4} & \mathbf{2 0 1 5} & \mathbf{2 0 1 6} & \mathbf{2 0 1 7} \\ \text { Acre } & \mathbf{2 , 5 6 \%} & 0,15 \% & 0,19 \% & 0,18 \% \\ \text { Alagoas } & \mathbf{4 9 , 2 7 \%} & \mathbf{3 6 , 8 0 \%} & \mathbf{3 5 , 3 3 \%} & 33,95 \% \\ \text { Amazonas } & 0,00 \% & 0,01 \% & 0,04 \% & 0,07 \% \\ \text { Goiás } & 2,79 \% & 3,03 \% & 4,46 \% & 3,59 \% \\ \text { Mato Grosso } & 0,02 \% & 0,05 \% & 0,10 \% & 0,15 \% \\ \text { Mato Grosso do Sul } & 3,40 \% & 4,25 \% & 7,04 \% & 6,88 \% \\ \text { Minas Gerais } & 2,24 \% & 2,59 \% & 4,02 \% & 3,97 \% \\ \text { Paraíba } & 0,81 \% & 1,38 \% & 1,35 \% & 4,25 \% \\ \text { Paraná } & 3,10 \% & 3,15 \% & 3,66 \% & 3,58 \% \\ \text { Pernambuco } & 2,44 \% & 2,93 \% & 2,27 \% & 1,93 \% \\ \text { Rio Grande do Norte } & 0,26 \% & 0,33 \% & 0,62 \% & 0,64 \% \\ \text { Rio Grande do Sul } & 0,00 \% & 0,01 \% & 0,02 \% & 0,01 \% \\ \text { Roraima } & 0,00 \% & 0,01 \% & 1,14 \% & 14,14 \% \\ \text { São Paulo } & 4,39 \% & 4,22 \% & 7,06 \% & 7,07 \% \\ \text { Sergipe } & 2,07 \% & 1,44 \% & 1,52 \% & 1,45 \%\end{array}$

Fonte: elaboração própria com base em dados da Secretaria de Comércio Exterior (SECEX) (Brasil, 2019a).

De forma geral, os resultados obtidos na Tabela 6 referentes ao indicador do comércio de açúcar em relação ao comércio total nos estados brasileiros apresentam valores relativamente menores em relação aos de participação relativa.

\subsection{ANÁLISE EXPLORATÓRIA DE DADOS ESPACIAIS}

A análise exploratória dos dados espaciais (AEDE) utilizada neste trabalho aborda os resultados obtidos através do I de Moran global, buscando verificar a correlação espacial global do valor das exportações de açúcar entre os estados brasileiros, para o período de 2014 a 2017, e também a análise de identificação de clusters locais, identificando a relação do valor das exportações de açúcar de cada município com seus respectivos vizinhos.

A Tabela 7 mostra os resultados obtidos no teste de I de Moran para identificar se a série do valor das exportações de açúcar é correlacionada espacialmente entre as unidades federativas brasileiras, durante esse período analisado. Conforme Almeida (2012), a hipótese nula do teste indica que a série não é correlacionada espacialmente e a hipótese alternativa é que a série possui correlação espacial entre as unidades territoriais analisadas.

$\mathrm{Na}$ Tabela 7, pode-se verificar que foi realizado o teste de correlação espacial global de Moran a fim de verificar a existência de dependência espacial na série tratada, utilizando as matrizes de contiguidade queen (rainha) e também a rook (torre). Os resultados mostram que, em todos os anos tratados no trabalho, a série valor das exportações de açúcar se mostrou significativa estatisticamente a um nível de significância de $5 \%$, tanto pela matriz rainha como pela torre. Assim, como o valor do I de Moran obtido é positivo, conclui-se que a série valor das exportações de açúcar apresenta dependência espacial global nos anos analisados, ou 
seja, os valores observados em um estado são afetados de forma positiva pelos valores apresentados dos seus vizinhos.

Tabela 7. Coeficiente I de Moran global univariado das exportações de açúcar das unidades federativas do Brasil, no período de 2014 a 2017

\begin{tabular}{ccccc}
\multicolumn{1}{c}{ Variáveis } & Rainha & p-valor & Torre & p-valor \\
Valor das exportações em 2014 & $0.1040 *$ & $(0.0220)$ & $0.1040^{*}$ & $(0.0220)$ \\
Valor das exportações em 2015 & $0.1214^{*}$ & $(0.0220)$ & $0.1214^{*}$ & $(0.0220)$ \\
Valor das exportações em 2016 & $0.0982^{*}$ & $(0.0180)$ & $0.0983^{*}$ & $(0.0180)$ \\
Valor das exportações em 2017 & $0.1020 *$ & $(0.0190)$ & $0.1020 *$ & $(0.0190)$ \\
\hline
\end{tabular}

Fonte: estimada pelo autor no software GeoDa, com base nos dados da pesquisa. Nota: pseudossignificância empírica baseada em 999 permutações aleatórias; *Significativo a um nível de significância de 5\%.

Além da análise univariada, em que se analisa espacialmente apenas uma série, são apresentados, na Tabela 8, os resultados obtidos no teste I de Moran bivariado, o qual trata da relação espacial entre o valor das exportações de açúcar e os níveis de emprego nesse setor. Conforme mostram Costa et al. (2006), a interação entre essas duas variáveis deve apresentar uma relação positiva, pois, quanto maiores os valores das exportações de açúcar, mais incentivos os produtores dessa commodity terão para contratar novos empregados.

De acordo com os valores obtidos na Tabela 8, pode-se observar que, para todos os quatro anos analisados, a hipótese nula de aleatoriedade espacial é rejeitada a um nível de significância de 10\%, por meio das matrizes rainha e torre. Portanto, pode-se concluir estatisticamente que o valor das exportações de açúcar e o número de empregos nesse mesmo setor são afetados espacialmente de maneira positiva, dado o sinal apresentado do teste.

Tabela 8. Coeficiente I de Moran global bivariado das exportações de açúcar e nível de emprego nesse setor nas unidades federativas do Brasil, no período de 2014 a 2017

\begin{tabular}{ccccc}
\multicolumn{1}{c}{ Variáveis } & Rainha & p-valor & Torre & p-valor \\
Exportações e emprego em 2014 & $0.0859^{* *}$ & $(0.0570)$ & $0.0859 * *$ & $(0.0570)$ \\
Exportações e emprego em 2015 & $0.0885^{* *}$ & $(0.0540)$ & $0.0885^{* *}$ & $(0.0540)$ \\
Exportações e emprego em 2016 & $0.0716^{* *}$ & $(0.0630)$ & $0.0716^{* *}$ & $(0.0630)$ \\
Exportações e emprego em 2017 & $0.0706 * *$ & $(0.0650)$ & $0.0706 * *$ & $(0.0650)$
\end{tabular}

Fonte: estimada pelo autor no software GeoDa, com base nos dados da pesquisa. Nota: pseudossignificância empírica baseada em 999 permutações aleatórias; **Significativo a um nível de significância de 10\%.

Como as séries analisadas nas Tabelas 7 e 8 apresentaram autocorrelação espacial global, parte-se para a análise espacial local, com o intuito de buscar identificar clusters espaciais pela análise individual de cada estado com seus vizinhos, por meio do I de Moran local, tal como definido na metodologia deste trabalho. Dessa forma, a Figura 4 retrata o mapa de cluster local univariado para o valor das exportações de açúcar.

Na parte (A) da Figura 4, tem-se o mapa Lista das exportações de açúcar dos estados brasileiros referentes a 2014. Então, com base nela, podem-se realizar algumas observações a respeito dos resultados encontrados. São obtidos três tipos de clusters espaciais entre os 27 estados brasileiros: um é do tipo baixo-alto, composto apenas do Rio de Janeiro, que apresenta um baixo valor das exportações de açúcar e possui vizinhos com alto valor dessa variável, como é o caso, por exemplo, de São Paulo, que é o estado disparado com o maior valor das exportações de açúcar; outro é do tipo baixo-baixo, composto dos estados do Maranhão e do Pará, e, neste caso, o baixo valor das exportações de açúcar em ambos é influenciado pelos também baixos valores das exportações dos seus estados vizinhos. Por fim, o principal cluster encontrado nesse mapa é definido como alto-alto e tem como pertencentes os estados do Paraná, de São Paulo e do Mato Grosso do Sul. Portanto, conclui- 
se que os altos valores das exportações de açúcar desses três estados são influenciados pelos altos valores das exportações de seus estados vizinhos.

(A) Clusters das exportações em 2014

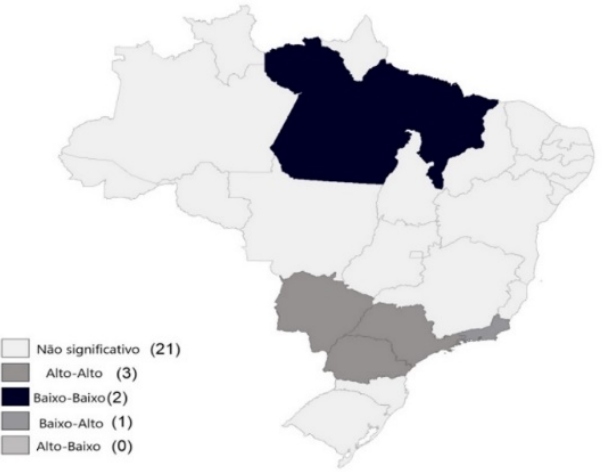

(B) Clusters das exportações 2017

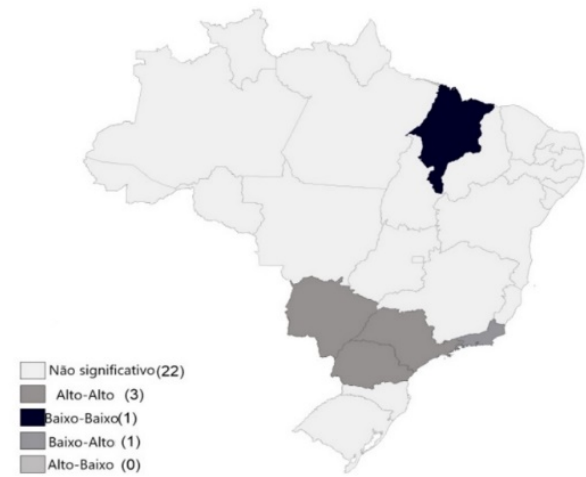

Figura 4. Mapa de clusters locais univariado das exportações de açúcar por unidades federativas do Brasil, em 2014 e 2017. Fonte: elaboração própria com base em dados do MDIC (Brasil, 2019a).

Em relação à análise univariada das exportações de açúcar em 2017, contida na parte (B) da Figura 4, pode-se verificar que, com exceção da saída do estado do Pará no cluster

baixo-baixo, os demais clusters apresentados em 2014 se repetem em 2017, mantendo um determinado padrão de correlação espacial durante o período. Novamente, assim como mostrado na análise dos clusters locais de 2014, o mais importante a observar na Figura 4B é o grupo de clusters alto-alto composto dos estados do Paraná, São Paulo e Mato Grosso do Sul, no qual se pode observar que existe um efeito transbordamento derivado das exportações de açúcar neles.

As exportações de açúcar podem influenciar diretamente outras variáveis econômicas em determinada região, como a renda e os níveis de emprego (Costa et al., 2006). Assim, por meio da análise bivariada do I de Moran local, que, a exemplo da análise univariada, também pode ser calculada pelo software GeoDa, foram obtidos mapas de clusters locais bivariados para as exportações de açúcar versus o nível de emprego no setor sucroalcooleiro, para os quatro anos do período de análise, porém, na Figura 5, estão contidos apenas o ano inicial da análise (2014) e o ano final (2017).

(A) Clusters bivariados das exportações e emprego em 2014

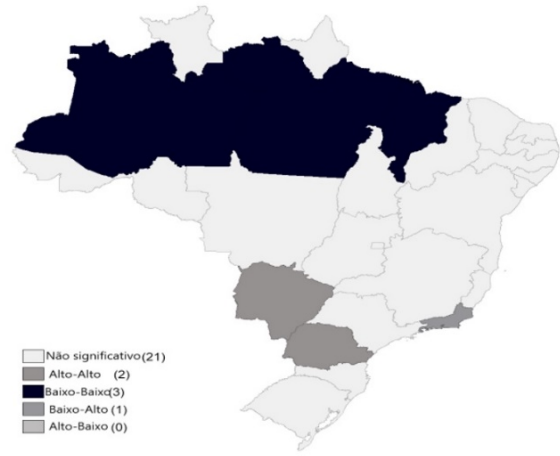

(B) Clusters bivariados das exportações e emprego em 2017

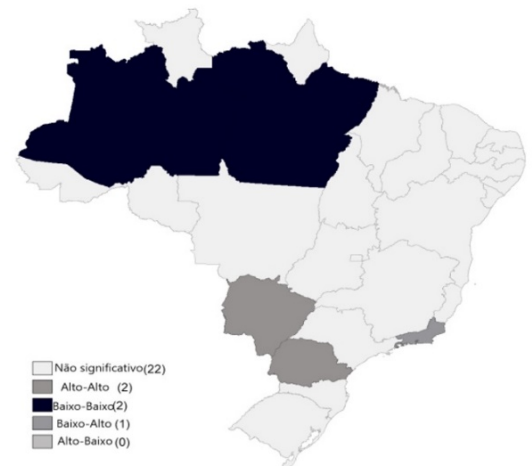

Figura 5. Mapa de clusters locais bivariado das exportações de açúcar com o emprego no setor sucroalcooleiro por unidades federativas do Brasil, em 2014 e 2017. Fonte: elaboração própria com base em dados do MDIC e da RAIS (Brasil, 2019a, 2019b).

A Figura 5 é dividida em parte (A) e (B): na primeira, tem-se o mapa de clusters locais bivariados para 2014, e, na segunda, para 2017. Em relação a 2014, é possível visualizar a existência de um cluster baixo-alto contendo apenas Rio de Janeiro, no qual um baixo valor 
das exportações de açúcar por esse estado está atrelado a altos níveis de emprego no setor sucroalcooleiro em seus estados vizinhos. Um outro cluster, agora do tipo baixo-baixo, é composto dos estados do Maranhão, do Pará e do Amazonas, podendo-se inferir que os baixos valores das exportações de açúcar nesses estados influenciam e são influenciados pelos baixos níveis de emprego nos vizinhos localizados em seus envoltórios. Por fim, o terceiro cluster local encontrado é o alto-alto, composto dos estados do Paraná e do Mato Grosso do Sul, em que o alto valor das exportações de açúcar nessas localidades está correlacionado espacialmente com altos níveis de emprego no setor sucroalcooleiro dos seus estados vizinhos.

No mapa de cluster local bivariado entre o valor das exportações de açúcar e o emprego no setor sucroalcooleiro em 2017, representado na Figura 5, é possível visualizar a baixa alteração nos grupos de clusters locais definidos em 2014. Nesse período, apenas houve a saída do estado do Maranhão do cluster baixo-baixo, dado não significativo estatisticamente a um nível de significância de 5\%, isto também por conta do leve aumento das suas exportações de açúcar em 2017, podendo ser recordado pela análise feita na da Figura $3 B$. Os demais clusters são os mesmos observados em 2014 e a análise correspondente segue a mesma linha de explicação utilizada no parágrafo anterior. Assim, a exemplo da análise univariada, na bivariada entre exportações de açúcar e emprego nesse setor, existem poucas alterações observadas no período observado neste trabalho.

Uma ressalva a ser feita é que pela escassez de trabalhos recentes utilizando essa temática e abordagem metodológica, eventuais comparações com pesquisas recentes ficaram limitadas. Assim, as análises foram realizadas segundo observações do autor baseadas nas fontes de dados utilizadas.

\section{CONSIDERAÇÕES FINAIS}

O presente trabalho realizou uma contextualização das exportações brasileiras de açúcar, identificando os volumes exportados das regiões e estados nacionais. Além disso, foram analisadas as correlações espaciais entre os estados brasileiros por meio das análises univariada e bivariada do I de Moran, utilizando, respectivamente, a variável valor das exportações de açúcar e o efeito das exportações de açúcar com o nível de emprego nesse setor, tendo como objetivo verificar a correlação espacial existente entre essas variáveis. Por fim, foram calculados alguns indicadores em relação ao comércio internacional, buscando-se verificar os níveis de competitividade e especialização do setor exportador de açúcar brasileiro. O período compreendido do trabalho foi de 2014 a 2017.

As exportações de açúcar, ao longo do período analisado, estiveram bastante concentradas em torno de alguns estados brasileiros. Em âmbito nacional, destaca-se a participação de São Paulo, com mais de $60 \%$ do valor total exportado de açúcar do Brasil, seguido de Paraná e Minas Gerais com mais de 10\% cada um. Em relação à região Nordeste, o estado de Alagoas é disparadamente o maior exportador de açúcar, com mais de $70 \%$ do total exportado durante o período analisado, e 6,21\% das exportações nacionais em 2014.

Os índices referentes aos níveis de competitividade e especialização dos estados brasileiros calculados neste trabalho comprovam que o estado mais especializado nas exportações de açúcar é Alagoas, devido também à sua baixa pauta exportadora dos demais produtos, comprovada pelo valor obtido no indicador de participação relativa do açúcar nas exportações totais, com um valor chegando a 93\% em 2014. O estado de São Paulo apresenta valores das exportações de açúcar bem mais elevados, porém o valor do quociente locacional é inferior pela menor participação das exportações de açúcar em relação ao total exportado, que girou em torno de $10 \%$ a 14\% durante o período de 2014 a 2017.

Os resultados obtidos na análise bivariada do I de Moran, a respeito do valor das exportações de açúcar com o nível de emprego desse setor comprovam que as exportações de açúcar, em uma determinada área i, estão correlacionadas estatisticamente com o nível de emprego nas suas localidades vizinhas. Na análise univariada das exportações de açúcar, são obtidas comprovações estatísticas, por meio do I de Moran, de que as exportações de açúcar em um estado afetam positivamente as exportações de açúcar nos seus estados 
vizinhos, como foi o caso dos estados do Paraná, de São Paulo e do Mato Grosso do Sul para todos os anos do período de análise deste trabalho.

Apesar dos esforços empregados na pesquisa, a discussão não se encerra com esses aspectos, portanto alguns questionamentos que podem surgir estão atrelados a atividades que possivelmente integram a montante e a jusante o processo de exportação de açúcar por meio de um modelo econométrico de dados em painel espacial. Outra questão que merece uma análise mais acurada é verificar se, com a soja, importante commodity de exportação, os resultados obtidos nesta pesquisa são similares ou divergem, e, em caso afirmativo, em quais pontos. Tais aspectos devem ser analisados em pesquisas futuras.

\section{REFERÊNCIAS}

Almeida, E. (2012). Econometria espacial aplicada (pp. 103-133), Campinas: Editora Alínea.

Alves, L. R. A., \& Bacchi, M. R. P. (2004). Oferta de exportação de açúcar do Brasil. Revista de Economia e Sociologia Rural, 42(1), 9-33. http://dx.doi.org/10.1590/S0103-20032004000100001

Anselin, L. (2003). Spatial externalities, spatial multipliers, and spatial econometrics. International Regional Science Review, 26(2), 153-166. http://dx.doi.org/10.1177/0160017602250972

Atlas da Complexidade Econômica (2016). Harvard's Center for International Development. Ranking de complexidade econômica por país e por produto. Recuperado em 24 de julho de 2020, de atlas.cid.harvard.edu.

Banco Central do Brasil. (2019). Sistema gerador de séries temporais (SGS). Recuperado em 13 de fevereiro de 2019, de https://www3.bcb.gov.br/sgspub/localizarseries/localizarSeries.do?method=prepararTelaLocalizarS eries

Brasil. Ministério do Desenvolvimento Indústria e Comércio Exterior - MDIC. Secretaria de comércio exterior (SECEX). (2019a). Brasília. Recuperado em 13 de fevereiro de 2018, de http://comexstat.mdic.gov.br/pt/geral

Brasil. Ministério da Economia. Relação Anual de Informações Sociais - RAIS. (2019b). Dados de emprego no setor açucareiro. Recuperado em 13 de fevereiro de 2018, de http://www.rais.gov.br/sitio/tabelas.jsf

Bueno, M. S. (2012). Análise da cadeia logística de exportação de açúcar (Trabalho de iniciação científica). ESALQ-LOG, Universidade de São Paulo. Recuperado em 24 de outubro de 2018, de https://esalqlog.esalq.usp.br/upload/kceditor/files/2015/05/Analise-da-cadeia-logistica-deexportacao-de-acucar-BUENO-M.-S.pdf

Costa, C. C., Burnquist, H. L., \& Guilhoto, J. J. M. (2006). Impacto de alterações nas exportações de açúcar e álcool nas regiões Centro-Sul e Norte-Nordeste sobre a economia do Brasil. Revista de Economia e Sociologia Rural, 44(4), 609-627. http://dx.doi.org/10.1590/S0103-20032006000400001

Dias, L. C., Gibbert, G. M., \& Shikida, P. F. A. (2006). Competitividade do açúcar brasileiro no mercado internacional. Revista de Economia e Agronegócio, 4(4), 457-484. Recuperado em 24 de outubro de 2018, de https://www.revistarea.ufv.br/index.php/rea/article/viewFile/91/95

Ferreira, M. A. S., Souza, M. C., \& Teixeira, E. C. (2009). Determinantes da receita de exportação brasileira de açúcar e álcool. Revista de Economia Agrícola, 56(2), 47-59. Recuperado em 24 de outubro de 2018, de ftp://ftp.sp.gov.br/ftpiea/publicacoes/rea/n2/rea4-2-09.pdf

Instituto Nacional de Meteorologia - INMET. (2019). Banco de Dados Meteorológicos para Ensino e Pesquisa (BDMEP). Recuperado em 13 de fevereiro de 2018, de http://www.inmet.gov.br/portal/index.php?r=bdmep/bdmep

Monasterio, L. (2011). Indicadores de análise regional e espacial. In B. O. Cruz, B. A. Furtado, L. Monasterio \& W. Rodrigues Júnior (Eds.), Economia regional e urbana. Brasília: Ipea. Recuperado em 26 de outubro de 2018, de http://desafios2.ipea.gov.br/agencia/images/stories/PDFs/livros/livros/livro_econregionalurbanaa.p df

Moran, P. A. (1948). The interpretation of statistical maps. Journal of the Royal Statistical Society. Series B. Methodological, 10(2), 243-251. http://dx.doi.org/10.1111/j.2517-6161.1948.tb00012.x

Shikida, P. F. A. (2014). Evolução e fases da agroindústria canavieira no Brasil. Revista de Política Agrícola, 23(4), 43-57. Recuperado em 24 de outubro de 2018, de https://seer.sede.embrapa.br/index.php/RPA/article/download/953/843 
Universidade de São Paulo - USP. Escola Superior de Agricultura "Luiz de Queiroz" - ESALQ. Centro de Estudos Avançados em Economia Aplicada - CEPEA. (2018). Açúcar. Recuperado em 13 de fevereiro de 2018, de https://www.cepea.esalq.usp.br/br/indicador/acucar.aspx

Vidal, M. F., Santos, J., \& Santos, M. (2006). Setor sucroalcooleiro no Nordeste brasileiro: estruturação da cadeia produtiva, produção e mercado. In Anais do XLIV Congresso da Sociedade Brasileira de Economia e Sociologia Rural (SOBER). Fortaleza. Recuperado em 24 de outubro de 2018, de https://www.agencia.cnptia.embrapa.br/Repositorio/Cadeia_produtiva_cana_Nordeste_000fizv2wfh 02wyiv802hvm3jme55p60.pdf

Submetido em: 17/Fev./2019.

Aceito em 23/Jun./2020

Classificação JEL: Q17 